\title{
Retraction
}

\section{Retracted: Necrotizing Fasciitis: Diagnostic Challenges and Current Practices}

\author{
ISRN Infectious Diseases
}

Received 17 November 2020; Accepted 17 November 2020; Published 21 December 2020

Copyright (c) 2020 ISRN Infectious Diseases. This is an open access article distributed under the Creative Commons Attribution License, which permits unrestricted use, distribution, and reproduction in any medium, provided the original work is properly cited.

ISRN Infectious Diseases has retracted the article titled "Necrotizing Fasciitis: Diagnostic Challenges and Current Practices" [1]. The article was found to contain a substantial amount of material, without citation, from previously published articles, including the following sources:

(i) Eric J Kuncir, Areti Tillou, Charles R. St. Hill, Patrizio Petrone, Brian Kimbrell, Juan A Asensio. "Necrotizing soft-tissue infections," Emergency Medicine Clinics of North America, 2003. https:// doi.org/10.1016/S0733-8627(03)00089-0 [2].

(ii) Puvanendran R., Huey J. C., Pasupathy S. Necrotizing fasciitis. Can Fam Physician 2009; 55: 981-7 [3].

(iii) Ellie J. C. Goldstein, Daniel A. Anaya, E. Patchen Dellinger; Necrotizing Soft-Tissue Infection: Diagnosis and Management, Clinical Infectious Diseases, Volume 44, Issue 5, 1 March 2007, Pages 705-710, https://doi.org/10.1086/511638 [4].

(iv) Qaali A. Hussein, Daniel A. Anaya. "Necrotizing Soft Tissue Infections," Critical Care Clinics, 2013. https://doi.org/10.1016/j.ccc.2013.06.001 [5].

(v) Miguel Cainzos and Francisco J. Gonzalez-Rodriguez, "Necrotizing soft-tissue infections," Current Opinion in Critical Care, 08/2007. https://doi.org/ 10.1097/MCC.0b013e32825a6a1b [6].

The article [1] includes an overlap of 1,174 words with Kuncir et al. [2], 1,135 words with Puvanendran et al. [3], 1,056 words with Goldstein et al. [4], 318 words with Hussein and Anaya [5], and 179 words with Cainzos and Gonzalez-Rodriguez [6].

The authors could not be contacted.

\section{References}

[1] A. Vijayakumar, R. Pullagura, and D. Thimmappa, "Necrotizing fasciitis: diagnostic challenges and current practices," ISRN Infectious Diseases, vol. 2014, Article ID 208072, 8 pages, 2014.

[2] E. J. Kuncir, A. Tillou, C. R. Hill, P. Petrone, B. Kimbrell, and J. A. Asensio, "Necrotizing soft-tissue infections," Emergency Medicine Clinics of North America, vol. 21, no. 4, 2003.

[3] R. Puvanendran, J. C. Huey, and S. Pasupathy, "Necrotizing fasciitis," Canadian Family Physician Medecin de Famille Canadien, vol. 55, no. 10, pp. 981-987, 2009.

[4] E. J. C. Goldstein, D. A. Anaya, and E. P. Dellinger, "Necrotizing soft-tissue infection: diagnosis and management," Clinical Infectious Diseases, vol. 44, no. 5, pp. 705-710, 2007.

[5] Q. A. Hussein and D. A. Anaya, "Necrotizing soft tissue infections," Critical Care Clinics, vol. 29, 2013.

[6] M. Cainzos and F. J. Gonzalez-Rodriguez, "Necrotizing soft tissue infections," Current Opinion in Critical Care, vol. 13, no. 4 , p. 433, 2007. 